Novels for Children and Young People, edited by Michelle Ann Abate and Gwen Athene Tarbox (2017). Altogether, however, despite having been published a few years ago, On the Graphic Novel remains a highly informative study. Although García professedly addresses himself to comics scholars, specialists and practitioners as well as general readers, his dazzling erudition, enounced in a multilingually sourced bibliography, also makes this study a perfect textbook for university courses in comics and graphic novels.

Malini Roy

\title{
Journey through Magic and Imagination
}

Michael Levy \& Farah Mendlesohn. 2016. Children's Fantasy Literature: An Introduction. Cambridge: Cambridge University Press. 245 pp. ISBN 978-1-10761029-3

DOI: 10.21066/carcl.libri.2017-06(02).0008

Throughout its history, the development of children's literature has been significantly influenced by various works of the fantasy genre. Nowadays a wide-ranging genre, written not only for children, fantasy literature stems from works which were created for or accepted by a child audience. Although it has always been an important part of children's literature, there are not many theoretical works related to it. Sharing their extensive knowledge of the topic, Michael Levy and Farah Mendlesohn have made a relevant contribution to the study of this field with their monograph Children's Fantasy Literature: An Introduction. Published in 2016 by Cambridge University Press, the book is a result of the continuing collaboration of the authors, their colleagues, and students. As the authors state in their introduction, the aim of the book is to link the criticism of fantasy literature and children's literature in general, because of the strong interrelation of the two genres.

Levy and Mendlesohn have succeeded in finding a manner of expression which can easily be understood by scholars and experts, but also those whose knowledge of fantasy is not yet extensive. Children's Fantasy Literature gives a broad and detailed overview of the development of fantasy literature in the English-speaking world, but its language is still quite accessible to the general reader. In nine chapters, the authors present the most prominent authors and works, as well as the social and political background of the times they belong to. The focus is mainly on the works from British and American literary traditions, but the legacy of the most influential writers of other nations (such as H.C. Andersen and C. Perrault) are also included. The book highlights information about certain influential authors in separate sections.

Although the study of fantasy literature is not highly developed, there are many classifications and categorisations within the genre. In one of her earlier works, Rhetorics of Fantasy (2008), Mendlesohn proposed four subdivisions of the literature of the fantastic: the portal-quest fantasy, the intrusion fantasy, the immersive fantasy, and the liminal fantasy. In the portal-quest fantasy, the everyday world and the fantastic exist separately, connected by magical portals, whereas in immersive fantasy the primary world is the fantastic one. In the intrusion fantasy, the fantastic interferes with the everyday. Liminal fantasy does not include a clear distinction between what is considered fantastical by the protagonist or 
by the reader. Along with some other descriptions and classifications, Children's Fantasy Literature relies on these four types of fantasy. They are presented in the introduction, which also includes an overview of the most important segments of the book, which thus helps the reader work through the rest of the book.

As mentioned above, the core of the book encompasses the development of children's fantasy in a historical context. The first chapter, "How fantasy became children's literature", explains that the first works of what is today considered to be children's fantasy were actually not intended for a young audience. The $15^{\text {th }}$-century publication of Aesop's Fables, beside its moral perspective, is well known for providing social critique. Perrault's fairy tales were created as an amusement for French salons. Only later were those stories accepted by children, usually after adults had started using them for educational purposes.

Britain in the $17^{\text {th }}$ century believed that children were in need of serious moral instruction, which made fantasy literature of the time not always easy to defend. Many authors pointed out that their magical characters were created to teach what is right. On the other hand, the $18^{\text {th }}$ century introduced the question of national identity. Folktales and traditions became a source of inspiration for authors such as the Brothers Grimm. The Romantic Movement gradually revealed a new perspective which defended imagination. The fantastic began to be seen as a way of perceiving the transcendental, an awakening of, as Coleridge said, "a love for the Great and the Whole" (quoted in Levy \& Mendlesohn 2016: 25) in both young and adult readers. As explained in the second chapter, Victorian fascination with childhood led to a crucial change: the child became the protagonist whose innocence, so greatly emphasised during the period, made the child stand out as a moral actor in the world.

Although the works under focus are mainly British, the third chapter explores American fantasy, which had a different beginning. European immigrants brought their folklore with them, but the Puritan spirit appreciated the rational. Apart from some adaptations of myths and legends (such as those of N. Hawthorne), or fantasy stories appearing in magazines (which were usually not very highly appreciated and were known as pulp), the realist tradition prevailed until the $19^{\text {th }}$ century and the appearance of authors such as L.F. Baum, and later E.B. White.

Chapters 4 and 5 describe some of the most relevant periods of children's fantasy: the inter-war and post-war period. Even though there were fewer possibilities to produce children's literature because of the wars, there were still authors whose work provided an outline of what children's fantasy should be. At the beginning of the war period, Edith Nesbitt laid the foundation for what Mendlesohn calls intrusive and portal-quest fantasy, as her characters discover the fantastic in everyday life. Something impressive was created by J.R.R. Tolkien, when he wrote The Hobbit. It was the first text with a world of its own, without any link to the world of the reader.

Levy and Mendlesohn describe the years after World War II as the golden age of children's fantasy, where the general forms of the genre were outlined. The role of the child faced another change: once expected to be innocent and kind, and as such a standard of morality, the child protagonist now becomes an active, responsible change-maker. The most outstanding representative of this idea was C.S. Lewis, whose characters in The 
Chronicles of Narnia are often entrusted with saving the world they are sent to. There was another surge of interest in folklore and indigenous traditions (as explained in Chapter 6), not only in Britain, but in some other English-speaking countries. All these concepts reflect the consequences of the difficult war years: many fantasy works show the world's need to overcome evil, restore peace, and put trust in the younger generation.

Though much of children's fantasy was inspired by what had already existed in tradition and folklore, new ideas, introduced by C.S. Lewis, directed fantasy towards mythopoeism - the creation of secondary fantastical worlds with their own culture, their own stories, completely apart from our own. This notion is explored in Chapter 7, which highlights Tolkien's Middle Earth as an excellent example. This chapter further explains the concept of medievalism, gender issues (the position of women), and inspiration found in non-European cultures.

In the last two chapters, the authors bring us to contemporary fantasy literature, marked by J.K. Rowling, Phillip Pullman, and the rapid development of the teen literature market. From the early 80 s or 90 s up until today, fantasy authors have created their works in response to issues relevant to contemporary youth, such as relationships and the search for one's own identity. By analysing many fantasy works problematising such concerns, the authors clearly explain the distinction between children's and young adult fantasy.

The development of children's literature, as well as literature in general, can always be seen as a reflection of the changes in a certain sociohistorical context. Children's Fantasy Literature offers thorough analyses of every important period in creating children's fantasy, and presents not only influential names, but also details which explain the general perspective of the time. A close study shows the shift in the notion of childhood, from its neglect and a belief in its need for moral guidance, through praise for its innocence, to trusting its independence and individuality. This all goes to show how fantasy actually reflects reality - sometimes criticising it, sometimes deriding it, and sometimes promoting belief in a better world.

The historical overview offers a good balance between British and American works, depicting their relationship, as well as the influence of other nations. However, even if we take into account the rapid and rich development of fantasy in recent years, parts of the book which describe contemporary fantasy can be seen as a minor drawback. Numerous plot summaries can sometimes make it difficult to distinguish the main (and valuable) ideas.

As Levy and Mendlesohn state in their introduction, children's fantasy is an enormous field of literary study, with many influential names, interpretations and categorisations, which cannot be covered in a single volume. Nevertheless, thanks to its many explanations and easily comprehensible language, Children's Fantasy Literature is likely to leave an important trace in the study of this immense, but still insufficiently developed, part of children's literature. The combination of a thorough historical paradigm and contemporary perspectives presented in this work may serve as a solid foundation for a deeper, more specialised study of this fascinating genre. 